Revista de Estudios Histórico-Jurídicos

[Sección historia del derecho europeo]

XL (Valparaíso, Chile, 2018)

[pp. $267-279$ ]

\title{
ANOTACIONES EN TORNO A LA REPRESIÓN DE LA MENDICIDAD Y LA VAGANCIA EN LA ESPAÑA DEL ANTIGUO RÉGIMEN Y SU SUSTITUCIÓN POR MEDIDAS DE SEGURIDAD
}

[Annotations Concerning the Repression of the Mendacity and the Vagrancy in the Spain of the Ancient Regimen and His Substitution for Safety Measures]

\author{
Luis RODRÍGUEZ ENNES* \\ Universidad de Vigo, España
}

\begin{abstract}
RESUMEN
El pauperismo y la vagancia constituyeron una de las lacras de la España del Antiguo Régimen. Con todo, sólo en el siglo XVIII se suscita una triple respuesta de la sociedad frente a los vagos: la generosa de la Iglesias y algunos particulares, la del Estado y la de proyectistas e intelectuales. Sin embargo, el termómetro más sensible para rastrear los intentos de solución es el de los escritores dieciochescos, entre los que Feijoo ocupa un lugar preeminente porque -movido por un fin utilitariodecididamente va a pedir la sustitución de las penas por medidas de seguridad.

Palabras clave

Vagancia - mendicidad - utilitarismo - medidas de seguridad.
\end{abstract}

\section{Abstract}

The poverty and the vagrancy constituted one of the blights of Spain of the Old Regime. With all that, only in the $18^{\text {th }}$ century a triple response of the society is provoked against the vagrants: the generous response to the Church and some individuals, to the State and to designers and intellectuals. Nevertheless, the most sensitive thermometer to trace the attempts of solution is that of the writers of the $18^{\text {th }}$ between those Feijoo occupies a pre-eminent place because -due to his utilitarian end- it is going to ask for the substitution of penalties for safety measures.

\section{KeYwords}

Vagrancy - poverty - utilitarianism safety measures.

RECIBIDO el 2 de marzo de 2018 y ACEPTADO el 31 de mayo de 2018

* Catedrático Emérito de Derecho Romano. Universidad de Vigo (España). Dirección postal: C/ Vilar no 49, Armentería, 36192 Pontevedra, España. Dirección electrónica: ennes@uvigo.es 
Los vagos suscitaron el interés y la preocupación de muy diversos sectores en la España del siglo XVIII ${ }^{1}$. Ha sido Domínguez Ortiz quien al tratar conjuntamente el pauperismo y la vagancia, ha fijado algunos conceptos fundamentales ${ }^{2}$. A su juicio "entre el pobre vergonzante, el mendigo público y el holgazán vagabundo las fronteras eran borrosas". "Junto a los auténticos menesterosos -explica Domínguez- un gran número de ociosos, de inadaptados sociales, pululaban por pueblos y caminos practicando la mendicidad o encubriendo su holgazanería con varios pretextos: unos se decían peregrinos, otros santeros, otros se dedicaban a la buhonería o se agregaban a las tribus de gitanos". La respuesta de la sociedad frente a los vagos es triple: la generosa de la Iglesia y algunos particulares, la del Estado y la de proyectistas e intelectuales. El Estado optó por una solución menos altruista. Durante mucho tiempo el único medio que empleó fue el de las levas forzosas, que proporcionaban al ejército un material humano de ínfimo valor ${ }^{3}$. Sin embargo, el termómetro más sensible para medir la preocupación, así como para rastrear los intentos de solución, es el de los escritores dieciochescos, entre los que -huelga decirlo- Feijoo ocupa un lugar preeminente.

Por supuesto todos coinciden en el diagnóstico del $\mathrm{m}$ a $\mathrm{l}$ como uno de los más agudos y perniciosos para la sociedad, la moral y la economía españolas. Esta uniformidad se rompe algo cuando llega la hora de aplicar una terapéutica, aunque, a decir verdad, hay una constante en los remedios que se aplican. En

${ }^{1}$ Campomanes formula este juicio rotundo: "Ni multiplican los bienes con el trabajo, ni tienen hijos porque no se casan, ni contribuyen al Erario, ni soportan las cargas concejiles, en una palabra, son tantos habitantes estériles para el servicio de Su Majestad y para la utilidad del Estado [Cfr. Informe original del Conde de Campomanes sobre la emigración de los habitantes de Galicia a Portugal, Biblioteca Nacional, ms. Núm. 18.574/12 cit. por A. MeıjIDE, La emigración gallega intrapeninsular en el siglo XVIII (Madrid, 1965) p. 23]. Vid. también RAMOS VÁZQUEZ, I., Policía de vagos para las ciudades españolas del siglo XVIII, en REHJUV. 22 (2010) p. 323-338. Es un trabajo extenso, que pese a su título, dedica gran parte del mismo a la policía de vagos de los siglos XV, XVI Y XVII.

2 Domínguez Ortiz, A., La sociedad española en el siglo XVIII.

${ }^{3}$ La Novísima Recopilación recoge en el libro XII, título XXXI, el conjunto de disposiciones sobre los vagos y "modo de proceder a su recogimiento y destino". En el reinado de Felipe V, las reales resoluciones sobre prender o recoger a los vagabundos (1725-1726) fueron completadas por otra disposición, en 1733, en la que se encargaba a las justicias que detuviesen en las cárceles y custodiasen a los vagabundos hábiles y de edad competente para el servicio de las armas. Fernando VI por real ordenanza de 13 de octubre de 1749, encargó a los corregidores "castigar a los ociosos", no consentir la existencia de "vagabundos a las armas o a obras públicas". Una real orden de 18 de noviembre de 1777, encargó a los corregidores "castigar a los ociosos", no consentir la existencia de "vagabundos ni gente [...] sin destino ni aplicación al trabajo y destinar a estos individuos a las armas o a obras públicas". Una real orden de $18 \mathrm{~d}$ enoviembre de 1777 expulsó de la Corte a todos los "pretendientes". Le siguieron las ordenanzas contra caldereros y buhoneros extranjeros que vagaban vendiendo efigie de yeso, botes de olor, palilleros, anteojos, cintas, hebillas, etc.; contra los santeros y saludadores; contra los que enseñaban cámaras oscuras, marmotas, osos, caballos, perros y otros animales hábiles; y contra los que a pretexto de estudiantes y con pasaportes de los maestros de escuela o rectores de las universidades, o como romeros y peregrinos y con pasaporte de los capitanes generales o magistrados políticos de estos reinos vagaban por ellos [cfr. al respecto: Anes, G., El Antiguo Régimen: Los Borbones (Madrid, 1975), pp. 153-156. Constituye el vol. IV de la Historia de España Alfaguara, dirigida por M. Artola]. 
lo que no hay duda, es en que fue un sector éste de los vagos muy propio para ensayar, al menos -y casi solo- teóricamente, planes que van de lo más realista a lo más descabellado, justificando la denominación de p r o y e c t is m o aplicado a un género como éste ${ }^{4}$. Por otra parte, ensayos como éstos vienen muy bien para que el pensador y escritor del XVIII lance planes de reforma tan característicos del espíritu de las Luces. Muchos son los autores que han afrontado el tema ${ }^{5}$, las más de las veces repitiendo -en términos parejos- remedios entre utópicos y pintorescos. Con todo, por su originalidad, una vez más hemos optado por ofrecer preferentemente el pensamiento de Feijoo y de su discípulo egregio Sarmiento.

Una de las más originales aportaciones feijonianas en punto a la erradicación de la picaresca, tan ínsita en nuestro espíritu nacional, estriba en la justificación del modus vivendi de los ociosos. En este sentido escribe: "Quien viste y come, no digo con lucimiento y regalo, sino medianamente uno y otro, sin tener renta, ni oficio con que lo gane, ni pariente o amigo que lo asista, de algún arte malo se socorre: o roba, o estafa, o trampea, o hace algún servicio inicuo ¿Pues qué se ha de hacer con Él? Lo que hacían los Corintios, Tradunt eum tortoribus. Entregarle al verdugo, para que le castigue si no revela y da pruebas de los fondos que le sustentan. Togados, jueces, no hay que quejarse de que se cometan hurtos, y no aparecen los ladrones. Los ladrones parecerían y desaparecerían los hurtos si se tomase esta providencia" ${ }^{\text {. }}$

Tal medio, consistente, pues, en la averiguación del patrimonio de los candidatos a delincuentes profesionales, arranca a Feijoo este irónico comentario metafórico: “¡Oh!, cuántas aves de rapiña con plumas de pavo se descubrirían en los pueblos tomando esta providencia" $"$.

Argumosa coincide con el sabio benedictino en el encargo a las justicias de

${ }^{4}$ Sobre esto, véase MuÑoz Pérez, J., Los proyectos sobre España y las Indias en el siglo XVIII: el proyectismo como género, en REP. 81 (1955), pp. 169-195.

5 CABRERA, J. DE., Crisis politica, determina el más florido Imperio y la mejor institución de Principes y Ministros (Madrid, 1719); MACANAZ, M. DE., Auxilios para bien gobernar una Monarquia Católica, en Semanario Erudito de Valladares, T. V., pp. 215-303; De Moya TORRES Y VeLasco, F. M., Manifiesto universal de los males que envejecidos España padece y de las causas de que nacen y remedios que a cada uno de su clase corresponde sin que tenga nota de arbitrio ante sí para que se conozca el daño de los que se establecieron (Madrid, 1700?); HeREDIA y BAZÁN, A., Representación al Rey sobre la importancia y facilidad de establecer Casas y Hospicios (Zaragoza, 1744); Aguado, A., Politica española para el más proporcionado remedio de nuestra monarquía (Madrid, 1746-1750); ÁlvareZ De BohórqueZ, D., Discursos varios sobre la despoblación de España, en que se proponen algunos medios para embarazar los perjuicios que se infieren de ella y el méthodo de augmentar la Población en la Monarquia (Madrid, 1755); Ponz, A., Viaje de España en el que se da noticia de las cosas más apreciables y dignas de saberse que hay en ella (Madrid, 1768).

${ }^{6}$ Feijoo, F. B. J. Paradoja octava: "Debería hacerse constar al Magistrado de qué se sustentan todos los individuos del pueblo", en Paradojas políticas y morales, en TCU, T. VI.

${ }^{7}$ Ibíd. Y añade en Discurso XIII: "La ociosidad desterrada y la milicia socorrida", en TCU, T. VIII: "En el Tomo V, Disc. I, Paradoja VIII, dejo escrito que hubo Repúblicas donde tomaba razón el Magistrado de los fondos que tenía cada uno para sustentarse. Si esto se hiciese en todos los Pueblos de España, yo sé que se descubrieran los autores de muchos grandes robos, que para siempre quedan ocultos. Esto se conseguiría, poniendo en prisión, como bastantemente indiciados del crimen de latrocinio, de estafa o trampa (que todo coincide) a todos aquellos, que se hallase portarse y sustentarse bien, sin tener oficio ni beneficio, o cuyo porte y sustento 
la realización y responsabilidad de esta tarea ${ }^{8}$. Ellos tendrían que encargarse, en los límites territoriales de su jurisdicción, de seleccionar a los verdaderos de los pobres fingidos, de remitir a éstos a sus lugares de procedencia, de lograr la manutención de aquellos en sus pueblos respectivos. Una vez llevada a cabo esta selección hay que ocupar al vago, y también en este quehacer será la justicia la autoridad inmediata que ordene el trabajo en función con las precisiones del lugar, o con lo que ella misma crea conveniente; en el campo, en la industria, en obras públicas o particulares 9 .

Feijoo va a extremar sus medidas de reinserción social proponiendo que también se destine a los "holgazanes y vagabundos" al servicio de las armas si se hallaren en condiciones de prestarles ${ }^{10}$, demostrando con ello su honda preocupación por la curación del endémico mal de la vagancia, en consonancia con la preocupación manifestada por los legisladores dieciochescos ${ }^{11}$.

También se dirige la acerba crítica feijoniana contra la perniciosa práctica de la limosna. En su Paradoja Nona, que lleva el expresivo título: "Gran parte de lo que se expende en limosnas, no solo se pierde, pero daña", escribe: "La limosna no aprovecha si no se distribuye con inteligencia, discreción y juicio. Una mano precipitada en dar, socorre a muchos pobres; pero al mismo tiempo sustenta a muchos holgazanes: no solo los sustenta, los cría; porque donde sin discreción se reparte copiosa limosna, muchos, que se aplicarían al trabajo para pasar la vida, se dan a la ociosidad, dispersándose de la fatiga propia a cuenta de la profesión ajena. Los daños, que aquí resultan para la República, son harto graves. Pierde muchos operarios y se le añaden muchos viciosos".

Feijoo, pese a su filiación monástica, se inscribe así, decididamente en la línea

exceda mucho al producto del oficio, o beneficio; y hecho esto, procediendo a una exacta pesquisa de su vida y milagros".

${ }^{8}$ De argumosa y Gándara, T. V., Erudición politica, despertador sobre el comercio, agricultura y manufacturas, con avisos de buena policía y aumento del Real Erario (Madrid, 1743).

${ }^{9}$ Así, dice el Padre Maestro. "Nunca faltaría en que hacerlos trabajar, ya labrando territorios incultos, ya componiendo caminos, ya sirviendo a la construcción de puentes u otros edificios públicos, ya plantando arboledas, ya persiguiendo y matando fieras donde las hay, etc. No sólo se lograría con esta providencia el beneficio de muchas obras útiles al común, más aún otro mayor, que es purgarse la República de muchos tramposos y ladrones, pues es innegable que muchos de los paseantes de calles, que no tienen tierras, ni rentas, ni oficio, sólo pueden vivir de trampas y hurtos" (cfr. loc. cit. en n.7).

10 "Supongo, que es inevitable la necesidad de mantener Tropas en el Reino, aún en tiempo de paz, y así siempre habrá que ocupar esta gente" (cfr. ibíd.).

${ }^{11}$ Sobre la legislación borbónica del XVIII, vid. la n. 3. Es curioso constatar, como unos doscientos años antes, Martín Lutero proponía soluciones semejantes al endémico problema de la mendicidad. A su juicio, los monjes mendicantes que pedían limosna no estaban realizando buenas obras, sino gastándose el dinero que debía ir a quienes realmente lo necesitaban. Creía que el dinero debía ir a un fondo común y emplearse para aliviar las necesidades de los pobres. Era un enfoque totalmente distinto en relación con la pobreza: la mendicidad había dejado de ser un símbolo de la virtud monástica para convertirse en un tema de justicia social. Como anécdota al respecto, Lutero refiere lo siguiente. "Se dice de San Martín que en un viaje que hizo curó a todos los enfermos. Se enteraron de ello un ciego y un cojo y se escaparon al acercarse el santo porque preferían seguir viviendo de la mendicidad [Cfr. Lutero, M., Martin Luthers Werke (Weimar, 1883), III, p. 602]. 
crítica de los ilustrados contra los abusos de la mendicidad. En este sentido, Ustáriz $^{12}$ pedía que la ley cayese con rigor sobre los vagos fuertes y sanos, obligándoles a abandonar la vida cómoda de pedigüeños, para que se acojan a una ocupación digna $^{13}$. Sin duda, es Bernardo Ward quien, en esta primera mitad de la centuria, aborda más a fondo el problema representado por la plaga de vagos que se ampara en la inmunidad y aquiescencia concedida a los mendigos ${ }^{14}$. Al estudiar las raíces de la ociosidad, llega a la conclusión de que el grueso de los vagos lo son voluntariamente, porque encuentran un medio ambiental propicio en el que pueden vivir sin trabajar. Es interesante contrastar como Ward, en su preocupación y en sus observaciones, llega a concluir que en la creación de un clima n a c i o $\mathrm{n}$ a $\mathrm{l}$ proclive a la vagancia, bien podía influir la veneración que el pueblo manifestaba hacia otros elementos que también vivían de limosna: los frailes mendicantes, que así actuarían de inconsciente atractivo para la vida ociosa ${ }^{15}$. La limosna, bien orientada y distribuida ${ }^{16}$, se tornaría en remedios de muchas necesidades pero,

12 UsTáRIZ, J. DE., Theórica y práctica del comercio y marina (Madrid, 1742). Sobre Ustáriz, cfr. Mounier, A., Les faits et la doctrine économique en Espagne sous Philippe V(1760-1732). Gerónimo de Ustáriz (Burdeos, 1919); HamiLTON, E. J., Nuevo examen del mercantilismo de Jerónimo de Ustáriz, en Florecimiento del capitalismo y otros ensayos de historia económica (Madrid, 1948).

13 "Y que a los demás, de mayor robustez y edad competente para ejercicios violentos, se apremien con las penas y disposiciones que prescriben las leyes del Reino a que busquen oficios y otras ocupaciones más proporcionadas a cada uno y se ganen la vida, sin permitirles que pidan limosna ni la busquen en los conventos”, ibíd., p. 136.

14 Ward, B., Obra Pía. Medios de remediar la miseria de la gente pobre de España (Valencia, 1750); ÉL MISMO, Proyecto económico. En el que se proponen varias providencias dirigidas a promover los intereses de España (Madrid, 1761). Al pensamiento de Ward le da un sesgo literario Meléndez Valdés en su discurso sobre la mendiguez [Obras Completas III, ed. Emilio Palacios Fernández (Madrid, 1997) p. 273-294] cuyos fragmentos tienen el carácter de un breve ensayo sobre un tema que Meléndez Valdés dominaba con precisión después de su experiencia en la reunión de los hospitales de Ávila en 1792, a la sazón en Zamora, ahora (1802) en excedencia forzada, demuestra un exacto conocimiento del problema de la mendicidad en la España del setecientos. La relación del estado actual de los hospicios sirve para comprobar las insuficiencias de esta institución benéfica, tanto porque no daba cumplida respuesta a los problemas reales que pretendía resolver como por su escasa repercusión en la conciencia de los ciudadanos. Con palabras radicales rechaza que la mendicidad esté justificada por los principios morales del Evangelio. Por eso exige como Ward y Feijoo que la limosna se haga de una manera responsable, no a los mendigos en persona, sino orientada a una institución pública que la administre. [Cfr. Palacios Fernández, E., Juan Meléndez Valdés, un ilustrado al servicio de las Luces, en Juan Meléndez Valdés en el segundo centenario de su muerte (1817-2017), Cuadernos Dieciochistas, 18 (Salamanca, 2017), p. 23 ss.].

15 "Con todo me hago cargo de que la mendicidad, tiene más raíces en nuestros países católicos que en los protestantes, por el abuso que se hace de las mejores cosas, y por la inteligencia errónea, que quiere dar el hombre a las cosas más santas calificando de virtud su pasión. La humildad de un religioso que pudiendo tener sus conveniencias se sujeta a vivir de la limosna, es sin duda de mucho ejemplo, y digna estimación; pero... aquello de ver juntas la mendicidad y la veneración, engendra en los ánimos... una impresión que en gente ruda que no sabe distinguir la pobreza religiosa de la mendicidad culpable, los inclina insensiblemente a la vida holgazana”. Cfr. Ward, B., Proyecto económico, cit. (n. 14), p. 198.

16 "Estas ayudas [para el funcionamiento de hospicios] habrían de provenir, primero de las donaciones de los Obispos, Monasterios, Cabildos, conventos y personas cualificadas, que al 
concedida sin discriminación, alimenta la proliferación y existencia de tantas gentes que olvidan cualquier forma de trabajo por resultarse la mendicidad más cómoda, segura y productiva ${ }^{17}$.

Empero, Manuel de Sistiernes y Feliú, Fiscal de lo Civil de la Real Audiencia de Barcelona y luego del Consejo de Castilla es, junto con Sarmiento y Campomanes, quien se muestra más realista ante el asentado problema de los vagos ${ }^{18}$. Sisternes, para precaver la ociosidad, propone como medida más inmediata atacar el recurso habitual y fácil del vago a vivir de esa limosna "que recogen de los monasterios y curas, o que se obligan a dar en las casas despobladas" ${ }^{19}$. Esta caridad, mal encauzada por los unos, y lograda violentamente por los otros, es susceptible de ser mejor dirigida, y aquí asoma el Sisternes proyectista. En principio, la limosna debía estar dedicada a los verdaderos pobres. El modo mejor de conseguir este fin consistiría en hacer responsables de su reparto a los párrocos y diputados de parroquias como mejores conocedores de las necesidades de sus convecinos. A ellos les podrían entregar las mandas y donaciones, los obispos, monasterios, sacerdotes e incluso particulares. Teme, sin embargo, las dificultades que podría suponer este socorro a través de intermediarios, menos directo y atractivo que el de ofrecer limosna ante la necesidad inmediata ${ }^{20}$. Por lo tanto, situándose en un plano más real, propone que se provea a los pobres - para acreditar que lo son- de una certificación del párroco y de una licencia de los justicias, y así saber el menos que la limosna se da al que lo necesita ${ }^{21}$. El método no era nuevo; se había ensayado ya en el siglo XVI a raíz de la R. O. de $1562^{22}$, y sus resultados

verse sin pobres (todos estaban ya recogidos) podrían dar a los hospicios lo que antes dedicaban a las limosnas”, cfr. WARD, B., Obra pía, cit. (n. 14), p. XXX. Feijoo plantea parejas medidas: "La invención de los hospicios es admirable para este efecto [si no se establecen] se puede suplir este preservativo universal contra la mendicidad viciosa con otro arbitrio; el cual es que todos los que dan diariamente limosnas a las puertas de sus casas, o sean Comunidades, o particulares, por medio de los domésticos que las distribuyan; averigüen, quienes son, y dónde moran los mendigos válidos, o capaces de trabajar, que acuden a ella; hecho esto lo avisen a la Justicia, la cual encarcelándolos luego al punto, en cumpliéndose un número suficiente, con público pregón harán constar a todos, que hay tantos hombres, y tantas mujeres ociosas, para los que necesitasen de sus servicios, o ya en el cultivo de los campos, en los oficios domésticos, acudan para que se les entreguen, con pena de doscientos azotes, o de galeras a los que desertasen”, cfr. FeIjoo, F. B. J., Paradoja nona: "Gran parte de lo que se expende en limosnas", cit. (n. 6), p. 85.

17 "Y otras personas caritativas, que hay por mala distribución - de las limosnas- sirven en gran parte de entretener la desidia y alimentar el vicio en gente tal, que más merece castigo que piedad", cfr. WARD, B., Proyecto económico, cit., (n. 14), p. 197.

18 Sistiernes y Feliú, M., Dictamen sobre la Casa Hospicio de Barcelona, Barcelona, 16 de agosto de 1770, A. C. A., Real Audiencia de Cataluña, Consultas, n 180, fols. 297-324; ID., Dictamen sobre los medios de desterrar la ociosidad y exterminar a los vagos, Barcelona, 1 de marzo de 1774, en ibíd. Cons. No 814, fols. 98-120.

${ }_{19}$ Ibíd. Dictamen sobre los medios, cit. (n. 18), fol. $101 \mathrm{v}$.

20 "Como cada uno es dueño de sus caudales y apenas hay nadie que no tenga conocida alguna necesidad del próximo, es regular que se incline a éste con preferencia de los demás, que pueda buscar una persona extraña. Así, pues serán muy pocos los que quieran dar sus limosnas a los curas, o Diputados de las parroquias, y a esto no se les puede obligar" (cfr. ibíd. fol. 120 r.).

${ }^{21}$ Ibíd. fol. $109 \mathrm{r}$.

${ }^{22}$ Nor. IV, 7, 39, ley 2a, p. 703: “Los verdaderos pobres solo pueden pedir limosna en los 
no habían sido del todo satisfactorios. La medida debía completarse exhortando, o mejor ordenando, a prelados y abades que se abstuvieran de dar limosnas en sus porterías, a no ser a los necesitados provistos de estas certificaciones. Los particulares serán dispensados de la carga que pesaba sobre sus patrimonios "de dar limosna y albergue a los pobres que pasen por sus puertas", entregando a cambio una cantidad equivalente a los hospicios, hospitales u otros centros benéficos. Por último, a los demás obligarles, incluso bajo la amenaza de castigos, a que dejen de dar limosnas por devoción o por "temor a ser asaltados en sus casas distantes de los poblados"23.

Tras la sustitución de las penas por medidas de seguridad se halla, sin duda, el fin utilitario, tan caro a los ilustrados. Este término suena a siglo XVIII, a Ilustración; ciertamente entonces autores como Foronda aconsejaban a los jueces que jamás castigasen sino con la mira de alguna utilidad ${ }^{24}$. También fue en aquel siglo cuando muchas obras públicas se hicieron con el trabajo de los condenados por delito. Como dice Tomás y Valiente: "las Obras Públicas de los Borbones a finales del XVIII se hicieron en buena parte gracias al trabajo de los reos condenados por delitos leves. El espíritu pragmático de aquellos gobernantes produjo no sólo resultados materialmente satisfactorios, sino también más justos y menos severos tratamientos punitivos" 25 . Con todo, es Sarmiento quien se va a situar a la cabeza de la corriente utilitarista yendo mucho más adelante que su maestro Feijoo, ya que emplea, incluso, estos argumentos de utilidad en pro de la supresión de la pena de muerte.

Así las cosas, para Sarmiento, el fundamento de la abolición es no solamente la inutilidad del castigo capital en su vertiente intimidatoria, sino sobre todo la posibilidad de obtener provecho de los mismos condenados ${ }^{26}$ : "Se han de colocar en donde por toda su vida nocere non possint; y trabajen en utilidad de la República, pero catenati como dijo Floro $^{27}$. Los Antiguos los condenaban a las canteras las

pueblos de su naturaleza y seis leguas en contorno [...] "so pena que el que pidiere limosna en otros lugares, sino en los que dicho es, sin tenerla dicha licencia, que por primera vez esté quatro días en la cárcel, y por la segunda ocho y sea desterrado por dos meses, y por la tercera le sea dada la pena de los vagamundos".

${ }^{23}$ Dictamen sobre los medios, cit., tols. 109-110 v.

${ }^{24}$ Foronda, V., Cartas sobre los asuntos más exquisitos de la Economía Politica y sobre las leyes criminales escritas por [...], (Madrid, 1794), II, pp. 189-190.

25 Tomás y Valiente, Francisco, El Derecho Penal de la monarquía absoluta (siglos XVI, XVII, XVIII) (Madrid, 1969), p. 366.

26 Sarmiento, Fr. M., Obra de Seiscientos Sesenta Pliegos, B. N. ms. 20.392, fol. 226.

27 El autor se refiere sin duda a Flor. 2, 33, 50-60; donde, tras narrar las vicisitudes de las guerras cántabras, alude en esos términos al triste destino que les esperaba a las poblaciones sometidas. 
unas, a los grandes edificios públicos, a los Caminos Reales, a limpiar puertos $^{28}$, etc., y a Islas Desiertas, o mal sanas" 29 .

Y añade un párrafo en favor de la deportación, -en la que se pensó varias veces en este siglo sin que nunca se llegara a realizar ${ }^{30}$ : "Si desde que se descubrió América se hubiese pensado en este arbitrio se ubieran utilizado muchos de los a ajusticiados; y otros que se debían ajusticiar. Oy estaría más poblada la América y no estaría España tan poblada de Ociosos y Gitanos".

Su argumentación es similar a la de Bentham y los utilitaristas ingleses ${ }^{31}$, sólo

${ }^{28}$ El Padre Maestro formula aquí un catálogo de las Servi Poenae romanas por las que el condenado pasaba a ser propiedad del Fisco y para distinguirlo de los otros Servi Caesaris, los juristas lo llamaban Servus Poenae -esclavo de la pena-. Sobre la esclavitud por condena, vid: Donatuti, G., La schiavitú per condanna, en BIDR. 42 (1934), pp. 219 ss.; en punto a los trabajos forzados en minas y canteras, cfr. RODRíGUEz ENNES, L., Extracción social y condiciones de trabajo de los mineros hispano-romanos, en Gallaecia, 13 (1991), pp. 1 ss.; ÉL MISMO, Las explotaciones mineras y la romanización de Gallaecia, en Libro Homenaje al Prof. Reimundo Yanes (Burgos, 2000), II, pp. 881 ss.

${ }_{29}$ Con todo, la deportatio in insulam, condena que reemplaza desde la época del emperador Tiberio a la interdicción del agua y el fuego, no es como las anteriores, una de las supplicia summa, ya que no lleva aparejada la pérdida del status libertatis, sino la de los derechos de ciudadanía; de ahí que los juristas la sitúen entre los supplicia mediocria (P.S. 5, 17, 2; D.48, 19, 2, 1).

${ }^{30}$ Como señaló Dorado Montero, P.: "La política del desembarazo es una política que no requiere gran esfuerzo mental y, por lo mismo, se ha practicado sin dificultad en todo tiempo y por donde quiera", cfr. s. v. Deportación, en Enciclopedia Jurídica Española -en adelante EJE(Barcelona, 1910) pp. 766 ss. Los grandes descubrimientos españoles permitieron hacer algunos ensayos de deportación cara a esas nuevas tierras, pero lo cierto es que España, a diferencia de Inglaterra y Francia, nunca adoptó una política sistemática de deportación de criminales. Con todo, en la segunda mitad del siglo XVIII, se comenzó a enviar penados a los presidios americanos, tal como por ese tiempo se hacía con los filipinos. En algunas leyes recopiladas se detallaba que la condena estuviera limitada al servicio de las armas, con el fin de mantener completos los requerimientos ultramarinos; pero también, en particular, a partir de las pérdidas españolas frente a Inglaterra en la llamada “Guerra de los Siete Años” (1756-1763), la pena se extendía a trabajos de fortificación. Desde 1763, tras ser devuelta Cuba por los ingleses, se reforzaron con celo todos los amurallamientos presidiales en toda la zona del Caribe, desde San Juan de Puerto Rico hasta Cartagena de Indias, pasando por La Habana y los puntos más estratégicos de México, especialmente Veracruz. Y para esta fatigante tarea se echó mano a delincuentes, si bien éstos en ningún caso llegaron a alcanzar la importancia numérica que en el Norte de África. Aunque todos no procedían de España, 1115 fue la cifra máxima de confinados, para el año 1769, en La Habana, el presidio más populoso de todos los americanos [Sobre esta cuestión vid.; PIKE, R., Penal Servitude in Early Modern Spain (Wisconsin, 1983) pp. 4 ss.]. Una política de confinamiento mucho más constante y significativa proyectaría España en el Norte de África. El sentimiento de la época respecto a África fue pronto, además, bien distinto al difundido sobre América. El propio Bartolomé de las Casas, celoso defensor de los indígenas americanos contra los rigores del invasor, no tuvo tapujos en contraponer el derecho de los indios a la barbarie del africano [Cfr. Konetzke, R., América latina: la época colonial ${ }^{12}$, trad. esp. P. Scarón (Madrid, 1981), p. 25]. Como ha apuntado Roldán Barbero, H.: “A fin de cuentas los musulmanes habían dominado Al-Andalus por espacio de ocho siglos y, tras su derrota, se enmarcaban sin ambages en el blanco de la animosidad. No existieron por eso miramientos benefactores a la hora de enrolar penados en los trabajos más duros de los fuertes africanos. Tierras bárbaras -se pensaba- debían ser pobladas por gente de ese jaez". [Cfr. Historia de la prisión en España (Barcelona, 1981), p. 18].

${ }^{31}$ Bentham, J., Tratados de legislación civily penal, trad. esp. Ramón Salas (Madrid, 1821) ed. Magdalena Rodríguez Gil (Madrid, 1981), p. 318 ss. 
que con la particularidad harto digna de encomio de que está expuesta más de medio siglo antes; de este modo se cumplen los dos fines de la pena: impedir que el reo cometa nuevos delitos, incapacitándolo para causar daños y enmendándolo por el trabajo y evitar que los demás le imiten en el porvenir, todo ello -al propio tiempo- presidido por el criterio utilitario: el hombre muerto no sirve para nada y los suplicios inventados para el bien de la sociedad deben ser útiles para ésta. Pensemos que el destierro a Australia como sustitutivo de la pena capital fue iniciado por los británicos en $1788^{32}$, dieciséis años después de la muerte de Sarmiento, es Concepción Arenal quien rechaza el establecimiento de colonias penales similares en $1895^{33}$.

Es cierto que las ideas de Sarmiento estaban en el ambiente o, al menos, en los sectores más refinados y progresivos de España; sin ir más lejos Voltaire, riguroso contemporáneo del sabio benedictino, arremetió a fondo contra la pena capital, no repudiándola en nombre de la humanidad o de la justicia sino movido por razones de utilidad coincidentes punto por punto con las sarmientanas ${ }^{34}$. Esa identidad de pensamiento nos induce a pensar en un conocimiento de las tesis volterianas por parte de nuestro autor; conocimiento, por otra parte, más que normal en Sarmiento, habida cuenta de su consabida puesta al día en lo que atañe al pensamiento ilustrado francés ${ }^{35}$. Es sabido que los obispos censuran la pene-

${ }^{32}$ La colonización británica de Australia se inició en 1788 con los “convicts” del capitán Philipp, en Port Jackson (Sidney). En efecto, para resolver las dificultades planteadas por el exceso de población en las cárceles inglesas, el gobierno británico decidió convertir a Australia en una colonia penitenciaria. Vid., al respecto, entre otras, CLARK, J. G., A short history of Australia (Londres, 1973); García ZarZa, E. G., Australia. El territorio, su historia, población y economía (Salamanca, 1976); LACOURT-GAYET, F., A concise history of Australia, Londres, 1983. El mismo destino tuvo la Guayana francesa que de 1794 a 1805 fue lugar de deportación.

33 Concepción Arenal, Las colonias penales de la Australia y la pena de deportación, en Obras Completas (Madrid, 1895), X, pp. 19 ss. Sobre el pensamiento de la penitenciarista ferrolana en este punto, cfr. Pereira Porto, L., A aportación de Concepción Arenal no marco do estado liberal español (A Coruña, 1997), pp. 128 ss. Es lógico que una vez que ya se regularizó la cárcel como pena fundamental, la deportación deje de ser una válvula de escape. Acerca de este proceso sustitutivo de las condenas de deportación por la de prisión, vid.: IGNATIEFF, M., A Just Mesure of Pain. The Penitentiary in the Industrial Revolution (Columbia, 1980), pp. 80 ss.

${ }^{34}$ Voltaire, en su comentario a la obra de Beccaria, escribe: "Es evidente que veinte ladrones vigorosos, condenados a trabajar en las obras públicas todo el curso de sus vidas, son útiles al Estado por sus suplicios, y que su muerte es únicamente útil para el verdugo, que se paga par que mate a un hombre en público. Los ladrones en Inglaterra son rara vez castigados a muerte: lo que se hace es transportarlos a las colonias" [Cfr. DEL VAL, J. A., Estudio introductorio a la ed. de Beccaria (Madrid, 1990), p. 133]. Notoria influencia de Voltaire en ForondA, V., Cartas sobre los asuntos más exquisitos de la Economía Política y sobre las leyes criminales (Madrid, 1789 y 1794), 2 vols. A la similitud de posiciones entre Sarmiento y Voltaire en punto al rechazo de la utilidad de la última pena, alude también GonZÁlez GuITIÁn, L., ¿Un precursor de Beccaria?, cit., p. 84: "por encima de hondísimas diferencias, el espíritu del tiempo casi identifica al P. Sarmiento y a Voltaire en su enemiga al último suplicio”.

${ }^{35}$ Es más que expresiva al respecto la carta que dirige a Feijoo en 1739: "La inmensa tardanza de los libros de Francia me hace mucho daño" (Cfr. Cartas de Samos, 27 de junio de 1739). Testimonios tan paladinamente claros como el que acabamos de transcribir convierten en hueras las palabras de López Peláez, A., cuando afirma refiriéndose al libro de Beccaria: "bastaría que fuese tan aplaudido por los enciclopedistas, y en especial por Voltaire para que Sarmiento lo 
tración de autores peligrosos, desde Grocio a los filósofos (Voltaire, Rousseau o Montesquieu). En cambio, los católicos ilustrados, plenamente ortodoxos, buscan esos libros por la necesidad que sienten de conocer el pensamiento europeo ${ }^{36}$. Cómo se formaron esos hombres, católicos sinceros, pero que no renuncian a las razones de la inteligencia, que quisieron hermanar revelación y razón, crítica histórica con verdad cristiana, naturaleza y gracia..., constituye un problema histórico arduo y complejo. De ahí que las radicales palabras de Sarmiento de rechazo al pensamiento volteriano se nos muestren, pues, más aparentes que reales, por lo menos en punto a la búsqueda de sustitutivos para la pena de muerte ${ }^{37}$.

Mucho se puede escribir sobre los paralelismos de Sarmiento con sus coetáneos franceses, pero lo que de todo ello quedará claro será esta condición sarmientana de encuadrar todas las nuevas ideas de la Ilustración dentro de la doctrina religiosacatólica o, al menos, el no ir en su contra ${ }^{38}$. Con todo, dentro de la más estricta ortodoxia católica, Tomás Moro, decapitado por orden de Enrique VIII y hoy santificado por la Iglesia, sostuvo en el siglo XVI ideas similares, ya que señalaba al trabajo como servidumbre como la pena más frecuente -en su quimérico país utópico- preferible a la muerte, pues un hombre al que se obliga a un trabajo

mirase con prevención y antipatía y no se apropiara de ninguna de sus ideas" (Cfr. Los escritos de Sarmiento, cit., p. 158).

${ }^{36}$ Mayáns recibe Voltaire, Montesquieu o la Enciclopedia; Campomanes dirá con claridad: "Cuán poca razón tienen los que declaman contra la instrucción que nos viene de los libros extranjeros ignorando sin duda el aprecio que en todos los tiempos hicieron de ellos nuestros mayores". Y las bibliotecas de Meléndez Valdés y de Jovellanos demuestran el conocimiento que tenían de los autores ilustrados europeos más representativos [Cfr. MESTRE, Antonio, La actitud religiosa de los católicos ilustrados, en El reformismo borbónico, GuIMÉRÁ, Agustín (ed.) (Madrid, 1996), p. 150].

37 "De Voltaire y de toda la cofradía de ateístas extranjeros con el primor de insolentes y desvergonzados, digo lo que Aretino respondió: Que no murmuraba de Dios porque no le conocía. Nada de esa canalla tengo ni entrará en mi celda. A fuerza me introdujeron un escrito de Voltaire para que le leyese. No me pesó haberle visto y leído, pues me ratifiqué en mi aversión por ese apóstol de la impiedad y la lujuria, como le llamó uno que escribió desde París. En cuanto leí ni un grano de instrucción recogí, ni me espanté de razones, ni tampoco me encantó con sus palabras [...] Por lo mismo, como yo no tengo esa púa al impío Voltaire ni a los de su cofradía, ninguno me encanta ni persuade" (Cfr. Carta a Armona, 1761). R. Herr hace un estudio detallado de las influencias de Voltaire en la cultura española sin que bajo la misma caiga nuestro benedictino. Voltaire va adquiriendo progresivamente fama de impío desde 1734, en que se le alaba abiertamente, hasta 1762 en que la Inquisición condena sus obras sin excluir ninguna. Referente a Feijoo, Herr escribe que en 1789 "un particular atacó las ideas de tolerancia religiosa de Rousseau y Voltaire y citó a Feijoo para refutarlas” [Cfr. España y la Revolución del siglo XVIII (Madrid, 1988), pp. 56 ss.]. Con todo, aún hay quien todavía hoy establece un paralelismo entre Feijoo y Voltaire, así Carr cuando apunta: "Feijoo desempeña en España el papel de un Voltaire; es un vulgarisateur de la Ilustración, y la mejor manera de enjuiciar las características de la Ilustración española es comparar la difusión de sus recopilaciones con la claridad de las Lettres philosophiques de Voltaire" [Cfr. España 1808-1939 (Barcelona, 1970), p. 87, n. 100].

38 Ceñal, R., Feijoo hombre de la Ilustración, en Revista de Occidente, 21 (2a época, 1964), pp. 313 ss., en donde apunta: "La Ilustración fuera de España tiene un carácter de continuidad de la modernidad ya iniciada con el Renacimiento y la Reforma mientras que en España supone una ruptura con una tradición, la cual, aunque de alguna manera operante en la modernidad europea, queda sin embargo rezagada y rota”. 
rudo, escribía, es más útil a la sociedad que un cadáver $^{39}$ y Sarmiento sin duda conocía la obra del canciller de Inglaterra. Pero no es menos cierto que la genial aportación sarmientana en el ámbito jurídico penal vaya a ser rodeada de un halo de desdoro por el mero hecho de que se haya apoyado en libros foráneos. Es obvio que sin la apuesta decidida en pro del avance de las ideas abolicionistas, sustentada por Sarmiento y otros conspicuos innovadores del siglo XVIII, estas ideas no encontrarían eco, no se habría dado cima a la magna tarea de la codificación y, con ella, al nacimiento del Derecho penal moderno. Los Borbones dieciochescos prosiguieron la misma línea de dureza punitiva practicada por sus antecesores y sólo cuando el Ancien Régime dejó su puesto al Estado Constitucional, la legislación penal pudo beneficiarse enteramente de las nuevas corrientes ${ }^{40}$.

\section{BiBLIOGRAFÍA}

Aguado, A., Política española para el más proporcionado remedio de nuestra Monarquía (Madrid, 1746-1750).

Álvarez de Bohórquez, D., Discursos varios sobre la despoblación de España, en que se proponen algunos medios para embarazar los perjuicios que se infieren de ella y el método de augmentar la población en la Monarquía (Madrid, 1755).

Anes, G., El Antiguo Régimen: Los Borbones (Madrid, 1975). Constituye el vol. IV de la Historia de España Alfaguara, dirigida por M. Artola.

Arenal, C., Las Colonias penales de la Australia y la pena de deportación, en Obras Completas, X (Madrid, 1895) p. 19 ss.

Bentham, J., Tratados de legislación civil y penal, trad. esp. (Madrid, 1980).

Cabrera, J. de., Crisis política determina el más florido Imperio (Madrid, 1719).

CAMPOMANES, Conde de, Informe original del Conde de Campomanes sobre la emigración de los habitantes de Galicia y Portugal, Biblioteca Nacional, ms. Núm. 18.574/12. CARr, R., España (1808-1939) (Barcelona, 1970).

Ceñal, R., Feijoo hombre de la Ilustración, en Revista de Occidente, 21 (2a época, 1969), pp. 313 ss.

${ }^{39}$ Hablando de los habitantes de Utopía, T. Moro dice: "[...] casi todos los delitos son castigados con la esclavitud. Están convencidos de que ésta no es menos terrible que la pena capital [...] un hombre que trabaja es más útil que un cadáver. Por otra parte, el ejemplo de su castigo inspira durante mucho tiempo en los demás un temor saludable" [Cfr. Utopía o tratado de la mejor forma de gobierno (trad. esp., Madrid, 1984), p. 165]. Parece que se está leyendo a Beccaria cuando nos describe al reo como una bestia de carga, que paga con sus esfuerzos la ofensa que ha cometido contra la colectividad. [Acerca de las influencias de Moro en Beccaria, véase FraILE, P., Un espacio para castigar. La cárcel y la ciencia penitenciaria en España (siglos XVIII-XIX) (Barcelona, 1987), pp. 60 ss.].

${ }^{40}$ Ya hemos tenido ocasión de apuntar la clara incompatibilidad entre el reformismo ilustrado y el sistema político absolutista. Dado que los absolutistas siguieron detentando el poder en toda Europa hasta el siglo XIX, P. Hazard escribió acertadamente que la "Aufklärung" actuó escindida en dos planos: el de la acción, que provisionalmente quedó inalterado, y el de la razón, en el que se preparaba la evolución que al fin se impondría realmente, cfr. El pensamiento europeo en el siglo XVIII (trad. esp. Julián Marías, Madrid, 1958), p. 57. Amplia bibliografía sobre la penalística clásica y moderna en RODRÍGUEZ ENNES, L., La lucha contra el arcaísmo punitivo del Antiguo Régimen, en REHJ. 22 (2010), pp. 323-348. 
Clark, J. G., A Short History of Australia (Londres, 1973).

De Argumosa y GÁNDARA, Erudición política, despertador sobre el comercio, agricultura y manufacturas con avisos de buena policía y aumento del Real Erario (Madrid, 1743), $\mathrm{V}$.

Del Val, J. A., Estudio introductorio a la obra de Beccaria (Madrid, 1990).

De Moya Torres y Velasco, F. M., Manifiesto universal de los males que envejecidos España padece y de las causas que nacen y remedios que a cada uno de su clase corresponde sin que tenga nota de arbitrio ante si para que se conozca el daño de los que se establecieron (Madrid, 1700).

Domínguez Ortiz, A., La sociedad española en el siglo XVIII (Madrid, 1955).

Donatuti, G., La schiavitú per condanna, en BIDR. 42 (1934), pp. 219 ss.

Feijoo, F. B. J., Teatro Crítico Universal, Paradojas políticas y morales (1 ${ }^{a}$ ed., Madrid, 1726), VI.

Foronda, V., Cartas sobre los asuntos más exquisitos de la Economía Politica y sobre las leyes criminales (Madrid, 1789 y 1794), 2 vols.

FraILE, P., Un espacio para castigar. La cárcel y la ciencia penitenciaria en España (siglos XVIII y XIX) (Barcelona, 1987).

García Zarza, E. G., Australia. El territorio, su historia, población y economía (Salamanca, 1976).

GonZÁlez GuItíñ, L., ¿Un predecesor de Beccaria?, en Estudios Penales y Criminológicos (Santiago de Compostela, 1988), I, pp. 60 ss.

Hamilton, E. J., Nuevo examen del mercantilismo de Jerónimo de Uztáriz, en Florecimiento del capitalismo y otros ensayos de historia económica (Madrid, 1948).

HaZARD, P., El pensamiento europeo en el siglo XVIII (trad. esp. Julián Marías, Madrid, 1958).

Heredia y BAZÁn, A., Representación al Rey sobre la importancia y facilidad de establecer Casas y Hospicios (Zaragoza, 1744).

Herr, R., España y la Revolución del siglo XVIII (trad. esp. Fernández Mel, Madrid, 1988).

Ignatieff, M., A Just Mesure of Pain. The Penitentiary in the Industrial Revolution (Columbia, 1980).

Konetzke, R., América latina: la época colonial (trad. esp. P. Scarón, Madrid, 1981).

LaCour-Gayet, F., A Concise History of Australia (Londres, 1983).

López Peláez, A., Un predecesor de Beccaria, en Revista Contemporánea, 52 (1898), pp. 493 ss.

LuTERo, M., Martin Luthers Werke (Weimar, 1883), III.

Macanaz, M. de., Auxilios para bien gobernar una Monarquía Católica, en Semanario Erudito de Valladares, V, pp. 215-303.

Meijide Pardo, A., La emigración gallega intrapeninular en el siglo XVIII (Madrid, 1960).

Meléndez Valdés, J., Discurso sobre la mendiguez, en Obras Completas (Madrid, 1997), III, pp. 272 ss.

Mestre, A., La actitud religiosa de los católicos ilustrados, en El Reformismo Borbónico, Guimerá, Agustín (ed.) (Madrid, 1996) p. 150 ss.

Moro, T., Utopía o tratado de la mejor forma de Gobierno (trad. esp., Madrid, 1984).

Mounier, A., Les faits et la doctrine économique en Espagne sous Philippe V (1700-1732). Jerónimo de Uztáriz (Burdeos, 1919). 
Muñoz PÉRez, J., Los proyectos sobre España y las Indias en el siglo XVIII: el proyectismo como género, en REP. 81 (1955), pp. 169-195.

N.O.R., XII, 31; IV, 7, 39.

Palacios Fernández, E., Juan Melendez Valdés, un ilustrado al servicio de las Luces, en Juan Melendez Valdés en el segundo centenario de su muerte (1817-2017), Cuadernos Dieciochescos 18 (Salamanca, 2017). pp. 23 ss.

Pereira Porto, L., A aportación de Concepción Arenal no marco do estado liberal español (A Coruña, 1997).

Pike, R., Penal Servitude in Early Modern Spain (Wisconsin, 1983).

PonZ, A., Viaje de España en el que se da noticia de las cosas más apreciables y dignas de saberse que hay en ella (Madrid, 1768).

Ramos Vázquez, I., Policías de vagos para las ciudades españolas del siglo XVIII, en REHJUV. 22 (2010).

RodríGUEZ ENNES, L., Extracción social y condiciones de trabajo de los mineros hispanoromanos, en Gallaeacia, 13 (1991), pp. 1 ss.

- Las explotaciones mineras y la romanización de Gallaecia, en Libro-Homenaje al Prof. Reimundo Yanes (Burgos, 2000), II, pp. 881 ss.

-La lucha contra el arcaísmo punitivo del Antiguo Régimen, en REHJUV. 22 (2010), pp. 323 ss.

RoldÁn Barbero, H., Historia de la prisión en España (Barcelona, 1981).

Sarmiento, Fr. M., Obra de Seiscientos Sesenta pliegos que trata de historia Natural y de todo género de Erudición con motivo de un papel que parece se habia publicado por los Abogados de La Coruña contra los Foros y Tierras que poseen en Galicia los benedictinos, Col. Dávila, Biblioteca Nacional, ms. 20.392.

Sistiernes y Feliú, M., Dictamen sobre la Casa Hospicio de Barcelona 16 de agosto de 1770, A. C. A., Real Audiencia de Cataluña, Consultas no 180, fols. 297-234.

- Dictamen sobre los medios de desterrar la ociosidad y exterminar a los vagos, Barcelona, 1 de marzo de 1774, en ibid. Cons. no 184, fols. 98-120.

Tomás y Valiente, F., El Derecho Penal de la monarquía absoluta (Madrid, 1969).

UzTÁrIZ, J. de, Theórica y práctica del comercio y marina (Madrid, 1742).

WARD, B., Obra Pía. Medios de remediar la miseria de la gente pobre de España (Valencia, 1750). 
